\title{
Diferentes taxas de alimentação de prensa do tipo expeller na eficiência de extração e na qualidade do óleo de semente de maracujá
}

\author{
Different screw press feed rates on extraction efficiency and quality of passion fruit seed oil
}

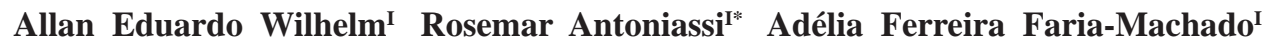 \\ Humberto Ribeiro Bizzo ${ }^{I}$ Sandro Luiz Rosa Reis ${ }^{I I}$ Sérgio Agostinho Cenci ${ }^{I}$
}

RESUMO

\begin{abstract}
Sementes de maracujá foram submetidas à prensagem sob diferentes taxas de alimentação $\left(1,2\right.$ a $\left.3,0 \mathrm{kgh}^{-1}\right)$ com o objetivo de avaliar o impacto desta variação no rendimento do processo de extração, nas características de qualidade e na composição em ácidos graxos do óleo de semente de maracujá. O rendimento de extração de óleo variou entre 24 e $25 \%$, com eficiência de 84 a $86 \%$ e teor residual de óleo na torta parcialmente desengordurada em torno de $5 \%$, indicando que o processo utilizado foi adequado à matéria-prima. O menor valor de temperatura de saída do óleo da prensa foi observado na taxa de alimentação de 2,4kgh-1. Não houve diferença significativa $(P>0,05)$ para a composição em ácidos graxos, estabilidade oxidativa, densidade e para os índices de iodo, saponificação, refração e de peróxidos. No entanto, houve diferença $(P<0,05)$ quanto ao teor de ácidos graxos livres, que foi menor para o óleo obtido na maior taxa de alimentação, e para umidade do óleo, que foi maior para a menor taxa de alimentação. A taxa de alimentação na prensagem de sementes de maracujá promoveu diferenças quanto à qualidade do óleo.
\end{abstract}

Palavras-chave: Passiflora edulis, ácidos graxos livres, umidade, estabilidade oxidativa, composição em ácidos graxos.

\section{ABSTRACT}

Passion fruit seeds were subjected to pressing under different feed rates (1.2 to $\left.3.0 \mathrm{kgh}^{-1}\right)$ in order to assess the impact of this variation in the yield of the extraction process, the quality characteristics and fatty acid composition of the passion fruit seed oil obtained. The yield of the process ranged between 24 and 25\% and presented 84 to $86 \%$ of efficiency and residual oil in partially defatted cake around $5 \%$, indicating that the procedure was adequate to the raw material. The lowest press oil outlet temperature was observed at the feed rate of $2.4 \mathrm{kgh}^{-1}$. No significant difference $(P>0.05)$ were observed for fatty acid composition, oxidative stability, density and iodine, saponification, refraction and peroxide values. However, significant differences $(P<0.05)$ was observed on free fatty acids content, which was lower for the highest feed rate, and oil moisture, which was higher for the lowest feed rate. The feed rate in pressing of passion fruit seeds promoted differences in oil quality.

Key words: Passiflora edulis, free fatty acids, moisture, oxidative stability, fatty acid composition.

\section{INTRODUÇÃO}

O maracujá-amarelo (Passiflora edulis) é um fruto apreciado pelo seu aroma e sabor exóticos, constitui fonte de vitamina $\mathrm{C}$, cálcio e fósforo e ainda possui em sua composição diversos compostos bioativos com reconhecidas propriedades terapêuticas, como glicosídeos, alcaloides e compostos fenólicos (DHAWAN et al., 2004). Nativo da América tropical, o maracujazeiro tem sido cultivado em praticamente toda a extensão dos trópicos, desde a América do Sul até a Austrália. Neste contexto, o Brasil ocupa papel de destaque como o maior produtor mundial do fruto, com 923.035 toneladas colhidas em 2011 (IBGE, 2013).

Apesar de ainda ser comercializado principalmente para o consumo direto "in natura", a industrialização do maracujá para produção de suco concentrado e polpa congelada tem obtido cada vez maior importância econômica. Ao fim do processamento, aproximadamente 70 a $80 \%$ do peso do fruto não é aproveitado pela indústria de suco, gerando um volume significativo de resíduos (FERRARI et al., 2004; LOPES et al., 2010). Países

\footnotetext{
IEmbrapa Agroindústria de Alimentos, Avenida das Américas, CP 29501, 23020-470, Rio de Janeiro, RJ, Brasil. E-mail: rosemar.antoniassi@embrapa.br. *Autor para correspondência.

IIExtrair Óleos Naturais, Bom Jesus do Itabapoana, RJ, Brasil. 
em desenvolvimento estão atualmente enfrentando importantes desafios associados à geração excessiva de resíduos provenientes do processamento de alimentos pela indústria. Muita ênfase tem sido dada em sua recuperação e beneficiamento, visando a amenizar aspectos relacionados à poluição e degradação do meio ambiente, além de vislumbrar sua utilização como possíveis novas fontes para geração de energia ou obtenção de componentes de alto valor agregado (GALANAKIS, 2012; OLIVEIRA et al., 2012).

As sementes são parte do resíduo gerado no processamento de maracujá e possuem elevado teor de óleo em sua composição. $\mathrm{O}$ óleo de semente de maracujá é composto predominantemente de ácidos graxos insaturados, principalmente oleico e linoleico, considerados de alto valor nutricional e tecnológico. Com base nestas evidências, diversos estudos têm sugerido forte potencial para aplicação desse óleo na indústria alimentícia, farmacêutica, cosmética e energética (FERRARI et al., 2004; LOPES et al., 2010; MALACRIDA \& JORGE, 2012). Além disso, a torta desengordurada obtida após a extração é fonte de fibras e proteínas, possui atividades antioxidante e antibiótica, e pode ser usada como ingrediente em diversos usos alimentícios (LÓPEZ-VARGAS et al., 2013).

As sementes do maracujá representam $4,23 \%$ em peso do fruto e apresentam umidade em torno de 14\% (OLIVEIRA et al., 2011). Para a extração de óleo de semente de maracujá por prensagem, é necessário remover o arilo, uma película que forma aglomerados de sementes e promove absorção de umidade e fermentação. A alta umidade da semente favorece a ação de lipases, enzimas que hidrolisam os triacilgliceróis, gerando ácidos graxos livres, com consequente redução da qualidade do óleo.

Alguns estudos verificaram a influência dos parâmetros de funcionamento da prensa na otimização da prensagem de oleaginosas em relação ao rendimento de óleo (KARAJ \& MULLER, 2011; PIGHINELLI et al., 2008). No entanto, a qualidade do óleo obtido pode sofrer severa influência das condições de utilização da prensa.

Neste estudo, a prensagem de semente de maracujá foi realizada utilizando-se diferentes taxas de alimentação de prensa para avaliar o impacto desta variação no rendimento do processo, no teor residual de óleo na torta e na temperatura de saída do óleo e nas características químicas, físicas e de qualidade do óleo obtido.

\section{MATERIAL E MÉTODOS}

Matéria-prima

Os frutos de Passiflora edulis foram processados em indústrias de sucos e polpas de maracujá instaladas nos Estados do Espírito Santo e Rio de Janeiro. As sementes resultantes deste processamento foram transportadas até a fábrica da Extrair - Óleos Naturais, instalada em Bom Jesus do Itabapoana (RJ), sendo em seguida lavadas em equipamento de aço inox, desenvolvido a partir do Aparelho de Decantação Experimental (REGIS, 2010), sob fluxo controlado de água e condições controladas de temperatura para promover o arraste das mucilagens com arilo e decantação das sementes limpas. Após a lavagem, as sementes foram secas por 15 minutos até atingir umidade abaixo de $10 \%$, em secador rotativo, adaptado com tela de inox, com capacidade de $1600 \mathrm{~kg}$ e dois exaustores para aquecimento até a temperatura máxima de $70^{\circ} \mathrm{C}$, sob fluxo direto de ar quente produzido por um forno a lenha. As sementes secas foram enviadas à Embrapa Agroindústria de Alimentos e armazenadas à temperatura de $-18^{\circ} \mathrm{C}$.

\section{Extração do óleo por prensagem}

A extração do óleo bruto foi realizada em prensa de laboratório do tipo expeller, modelo CA 59 G (Komet), com capacidade máxima de processamento de $5 \mathrm{kgh}^{-1}$ de matéria-prima. Foram utilizados parafuso com distância entre ranhuras de $12 \mathrm{~mm}$, malha de saída de óleo com orifícios de $1 \mathrm{~mm}$ de diâmetro e bocal de saída de torta com $10 \mathrm{~mm}$ de diâmetro. As sementes foram adicionadas à prensa sob taxas de 1,2, 1,8 e 2,4kgh-1, com velocidade de parafuso de $18 \mathrm{rpm}$ e de $3,0 \mathrm{kgh}^{-1}$ com velocidade de $24 \mathrm{rpm}$. A prensagem foi iniciada e, após 30min, considerou-se que o processo atingiu um estado estacionário. Após este tempo, óleo e a torta foram coletados durante o tempo estipulado de $30 \mathrm{~min}$ para cada tratamento. A temperatura do óleo foi aferida utilizando-se termômetro posicionado a $1 \mathrm{~cm}$ da malha de saída. O óleo obtido na prensagem foi centrifugado (Sorvall Legend XTR) por 10min a 10.000rpm a temperatura ambiente com o objetivo de separar qualquer resíduo de semente. O rendimento de extração de óleo (RO) foi calculado por balanço de massas entre a quantidade de semente utilizada e seu teor de óleo e a quantidade de torta gerada pela prensagem e seu teor de óleo residual (Equação 1).

$$
R O=\frac{(P s \times O s)-(P t \times O t)}{P s} \times 100 \%
$$

em que, Ps é a massa das sementes utilizadas (g) e Os é o conteúdo inicial de óleo das sementes utilizadas $\left(\mathrm{g}_{100 \mathrm{~g}^{-1}}\right)$, Pt é a massa da torta $(\mathrm{g})$, Ot é o conteúdo de óleo residual da torta $\left(\mathrm{g} 100 \mathrm{~g}^{-1}\right)$. A eficiência da extração, isto é, a capacidade da prensa em extrair 
o óleo contido na semente, foi determinada pelo quociente entre o rendimento em óleo na extração obtido pelo balanço de massas e o teor de óleo original da semente utilizada na prensagem.

Composição da semente e do óleo

O teor de umidade das sementes e das tortas obtidas por prensagem foi determinado segundo o método oficial Ca 2c-25 da AOCS (2009) em estufa Memmert modelo 500 a $103^{\circ} \mathrm{C} \pm 2^{\circ} \mathrm{C}$ até peso constante. $\mathrm{O}$ teor de óleo das sementes e das tortas resultantes da prensagem foi determinado por extração com éter de petróleo $\left(30-60^{\circ} \mathrm{C}\right)$, em aparelho Soxhlet, por $16 \mathrm{~h}$. O solvente foi evaporado em rotaevaporador e sob corrente de nitrogênio. $\mathrm{O}$ teor de ácidos graxos livres nos óleos foi determinado por titulometria, de acordo com o método oficial Ca 5a 40 da AOCS (2009) e o resultado expresso como ácido oleico. A análise do índice de peróxidos (miliequivalentes de peróxido por $1000 \mathrm{~g}$ de amostra) foi realizada de acordo com o método Cd 853 da AOCS (2009). O índice de estabilidade oxidativa (OSI) foi determinado em equipamento Rancimat 679 (Metrohm) a $110^{\circ} \mathrm{C}$, com taxa de ar de $10 \mathrm{Lh}^{-1}$ e $5 \mathrm{~g}$ de amostra de acordo com o método Cd 12b-92 da AOCS (2009). O índice de refração foi realizado em refratômetro tipo Abbé Bausch e Lomb a $40^{\circ} \mathrm{C}$ e a densidade foi determinada em densímetro digital AP PAAR DMA- 46 a $20^{\circ} \mathrm{C}$. Os dienos conjugados foram determinados de acordo com o método DGF C IV 6 (1984) em espectrofotômetro, modelo Agilent 8453. O teor de umidade em óleos foi determinado pelo método de Karl Fischer em equipamento Karl Fischer Titrino plus 870 (Metrohm).

\section{Composição em ácidos graxos}

Para composição em ácidos graxos, os ésteres metílicos foram obtidos de acordo com HARTMAN \& LAGO (1973). A cromatografia em fase gasosa foi realizada em cromatógrafo gasoso modelo Agilent 7890 com detector ionização de chama, utilizando-se coluna capilar de sílica fundida de $60 \mathrm{~m}, 0,32 \mathrm{~mm}$ de diâmetro interno e $0,25 \mu \mathrm{m}$ de fase estacionária de ciano propil siloxano na temperatura inicial de $100^{\circ} \mathrm{C}$, com programação de temperatura de 100 a $150^{\circ} \mathrm{C}$ na taxa de aquecimento de $50^{\circ} \mathrm{Cmin}^{-1}$, de 150 a $180^{\circ} \mathrm{C}$, com rampa de $1^{\circ} \mathrm{Cmin}^{-1}$, de 180 a $200^{\circ} \mathrm{C}$, com taxa de $25^{\circ} \mathrm{Cmin}^{-1}$ e mantida a $200^{\circ} \mathrm{C}$ por $15 \mathrm{~min}$. $\mathrm{O}$ injetor foi mantido a temperatura de $250^{\circ} \mathrm{C}$ no modo de divisão de fluxo (split) na razão de 50:1. Foi injetado um volume de $1 \mu \mathrm{L}$ de uma solução $2 \%$ em diclorometano. A temperatura do detector de ionização de chama foi de $280^{\circ} \mathrm{C}$ e o fluxo de gás de arraste $\left(\mathrm{H}_{2}\right)$ foi de $2,5 \mathrm{mLmin}^{-1}$ (medido a $40^{\circ} \mathrm{C}$ ). A identificação dos ésteres metílicos dos ácidos graxos foi realizada por comparação dos tempos de retenção com padrões da NU CHEK (Elysian, MN) números 62,79 e 87 e a quantificação foi realizada por normalização interna. A partir do perfil de ácidos graxos, o índice de iodo e de saponificação foram calculados.

\section{Análise estatística}

As análises físico-químicas foram realizadas em triplicata para cada tratamento. Os valores médios foram calculados e o teste de Tukey foi utilizado para avaliar a diferença significativa $(\mathrm{P}<0,05)$ entre os tratamentos.

\section{RESULTADOS}

As sementes do lote utilizado nos ensaios de prensagem apresentaram teor de óleo de 27,97\% $( \pm 0,07)$ em base úmida e está de acordo com faixa de 26,9 a 29,2\%, encontrada por REGIS (2010) para frutos de diversos estádios de maturação, cultivados na mesma região do Norte Fluminense. A umidade das sementes foi de $8,83 \%( \pm 0,21)$ e corresponde a um valor adequado para o correto funcionamento da prensa para obtenção de óleo de qualidade satisfatória.

A tabela 1 apresenta os parâmetros de extração do óleo de semente de maracujá. O rendimento em óleo obtido nos quatro tratamentos variou de 24,08 a 24,52\% com eficiência de extração de 86,09 a $87,66 \%$, que é uma variação discreta por se tratar de um processo contínuo. O teor de óleo residual na torta parcialmente desengordurada oscilou entre 5,17 a 5,61\% (base seca) para os tratamentos. Estes resultados são bastante satisfatórios e indicam a adequação do processo de extração à semente. A prensagem não é um processo de remoção completa do óleo da matriz e, em geral, o teor residual de óleo na torta é menor que $8 \%$, enquanto os farelos desengordurados obtidos na extração por solvente apresentam menos de $0,5 \%$ de óleo residual. Algumas matérias-primas que apresentam baixo conteúdo de fibras não obtiveram o mesmo desempenho na prensagem, com altos teores residuais de óleo na torta (PIGHINELLI et al., 2008). Outro estudo ainda observou variação no teor residual em função das diferenças nos parâmetros de processo (KARAJ \& MULLER, 2011). A prensagem é um processo factível, que se aplica a matérias-primas oleaginosas de baixa umidade como sementes e amêndoas com teor de óleo variável de 
Tabela 1 - Parâmetros de extração do óleo de semente de maracujá ${ }^{1}$ extraído por prensagem a frio sob diferentes taxas de alimentação de prensa.

\begin{tabular}{|c|c|c|c|c|}
\hline \multirow{2}{*}{ Parâmetros } & \multirow[b]{2}{*}{$1,2 \mathrm{kgh}^{-1}$} & \multirow[b]{2}{*}{$1,8 \mathrm{kgh}^{-1}$} & \multirow[b]{2}{*}{$2,4 \mathrm{kgh}^{-1}$} & \multirow[b]{2}{*}{$3,0 \mathrm{kgh}^{-1}$} \\
\hline & & & & \\
\hline Rendimento de extração ${ }^{2}(\%)$ & 24,43 & 24,18 & 24,52 & 24,08 \\
\hline Eficiência de extração ${ }^{3}(\%)$ & 87,33 & 86,46 & 87,66 & 86,09 \\
\hline Temperatura de saída do óleo $\left({ }^{\circ} \mathrm{C}\right)$ & 80 & 85 & 78 & 89 \\
\hline Teor de óleo da torta ${ }^{4}(\%)$ & 5,27 & 5,53 & 5,17 & 5,61 \\
\hline
\end{tabular}

${ }^{1}$ Teor de óleo da semente de $27,97 \%$ (base úmida) obtido por Soxhlet e $8,83 \%$ de umidade.

${ }^{2}$ Quantidade de óleo extraído da semente.

${ }^{3}$ Quantidade de óleo extraída em relação ao total.

${ }^{4}$ Valores em base seca

20 a $60 \%$. Atualmente, existem prensas contínuas disponíveis para pequena escala de produção, viabilizando a extração de óleo para matérias-primas que não tenham produção em grande escala, como ocorre para as oleaginosas extraídas por solvente (ANTONIASSI, 2013). Foi observada uma variação entre os tratamentos quanto à temperatura de saída do óleo, que oscilou entre 78 a $89^{\circ} \mathrm{C}$, indicando que, apesar de não ter sido utilizada qualquer fonte externa de calor durante a prensagem, não se trata de um processo de extração a frio, pois ocorre atrito interno na prensa em função das condições de processo e das características da própria semente. A temperatura aumentou quando se aumentou a taxa de entrada de matéria-prima e a velocidade do parafuso, no entanto, a menor temperatura foi obtida no tratamento em que foi utilizada a taxa de $2,4 \mathrm{kgh}^{-1}$. Quanto maior o volume de matéria-prima sob mesma velocidade de parafuso, maior é o atrito no interior da prensa. Entretanto, para taxas de alimentação mais baixas, sob mesma velocidade de parafuso, o tempo de residência é maior e consequentemente o material fica mais tempo em contato com as superfícies internas da prensa, elevando a temperatura do óleo.

As características físico-químicas e de qualidade do óleo estão apresentadas na tabela 2. Não houve diferença significativa $(\mathrm{P}>0,05)$ para densidade relativa e índices de refração, de saponificação e de iodo. Os valores de densidade relativa são semelhantes a outros óleos vegetais (FAO/WHO, 2001). Os índices de iodo e de saponificação refletem a composição em ácidos graxos enquanto o índice de refração é consequência não só dos ácidos graxos, mas também da geração de dienos conjugados. Os ácidos graxos conjugados são detectados nos óleos vegetais submetidos a processo de aquecimento, como desodorização durante o refino, fritura e outros (WHITE, 1995). Apesar das relativamente baixas temperaturas envolvidas na prensagem houve geração de dienos conjugados, o que pode ser explicado em virtude da alta concentração de ácido linoleico. Apesar do baixo nível de oxidação inicial avaliado pelo índice de peróxidos, que não foram detectados nos ensaios com maior taxa de alimentação e que foi menor que $1 \mathrm{meqkg}^{-1}$ para os demais, a estabilidade oxidativa oscilou de 6,38 a $6,79 \mathrm{~h}$. Estes resultados indicam baixa estabilidade e são semelhantes a outros óleos de semente de maracujá (REGIS, 2010) e ao óleo de girassol, que apresenta altos índices de ácido linoleico em sua composição e, por consequência, apresentam tendência à baixa estabilidade. Quanto à acidez do óleo, não houve diferença significativa $(\mathrm{P}>0,05)$ entre os tratamentos de $1,2,1,8$ e $2,4 \mathrm{kgh}^{-1}$. No entanto, o teor de ácidos graxos livres do óleo $(1,33 \%)$ obtido sob taxa de alimentação de prensa de $3,0 \mathrm{kgh}^{-1}$, foi significativamente menor $(\mathrm{P}<0,05)$ em relação aos outros tratamentos. $\mathrm{Na}$ prensagem com maior taxa de alimentação, em que também foi utilizada uma velocidade maior de parafuso (24rpm), o tempo de residência da matéria-prima no interior da prensa foi menor e, em conjunto com a maior temperatura observada no óleo, favoreceu uma redução mais rápida da umidade do material, o que possivelmente evitou a hidrólise do óleo durante o processo. A baixa acidez do óleo depende substancialmente do tempo decorrente da coleta até a lavagem e secagem da semente. Para este estudo, as sementes foram submetidas a processos de lavagem e secagem numa empresa que comercializa o óleo de semente de maracujá e pratica processos para evitar a hidrólise do óleo. Desta maneira, foi possível obter uma matéria-prima adequada ao processo de prensagem, o que ficou evidenciado pela boa qualidade do óleo obtido. Os valores encontrados no estudo, de, no máximo 1,57\% de ácidos graxos livres, atendem aos parâmetros máximos estabelecidos pela 
Tabela 2 - Características físico-químicas de óleo de semente de maracujá extraído por prensagem sob diferentes taxas de alimentação.

\begin{tabular}{|c|c|c|c|c|}
\hline \multirow{2}{*}{ Características } & \multicolumn{4}{|c|}{ 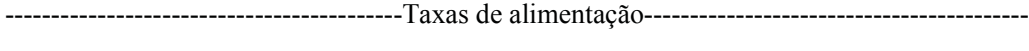 } \\
\hline & $1,2 \mathrm{kgh}^{-1}$ & $1,8 \mathrm{kgh}^{-1}$ & $2,4 \mathrm{kgh}^{-1}$ & $3,0 \mathrm{kgh}^{-1}$ \\
\hline Densidade relativa $\left(20^{\circ} \mathrm{C} / 20^{\circ} \mathrm{C}\right)$ & $0,92(0,00)^{\mathrm{a}}$ & $0,92(0,00)^{\mathrm{a}}$ & $0,92(0,00)^{\mathrm{a}}$ & $0,92(0,00)^{\mathrm{a}}$ \\
\hline Índice de Estabilidade oxidativa (h) & $6,38(0,13)^{\mathrm{a}}$ & $6,66(0,15)^{\mathrm{a}}$ & $6,79(0,19)^{\mathrm{a}}$ & $6,79(0,16)^{\mathrm{a}}$ \\
\hline Índice de Peróxidos (meqkg $\left.{ }^{-1}\right)$ & $0,82(0,12)^{\mathrm{a}}$ & $0,42(0,00)^{\mathrm{a}}$ & ND & ND \\
\hline Ácidos graxos livres ${ }^{1}(\%)$ & $1,55(0,04)^{\mathrm{a}}$ & $1,54(0,01)^{\mathrm{a}}$ & $1,57(0,00)^{\mathrm{a}}$ & $1,33(0,06)^{\mathrm{b}}$ \\
\hline Dienos conjugados $(\%)$ & $0,15(0,00)^{\mathrm{a}}$ & $0,15(0,01)^{\mathrm{a}}$ & $0,15(0,00)^{\mathrm{a}}$ & $0,15(0,00)^{\mathrm{a}}$ \\
\hline Umidade $(\%)$ & $0,26(0,03)^{\mathrm{a}}$ & $0,14(0,01)^{\mathrm{b}}$ & $0,14(0,01)^{\mathrm{b}}$ & $0,11(0,00)^{\mathrm{b}}$ \\
\hline Índice de refração $\left(\mathrm{nD} 40^{\circ} \mathrm{C}\right)$ & $1,4657(0,0015)^{\mathrm{a}}$ & $1,4665(0,0005)^{\mathrm{a}}$ & $1,4665(0,0000)^{\mathrm{a}}$ & $1,4663(0,0006)^{\mathrm{a}}$ \\
\hline Índice de iodo $\left(\mathrm{g} 100 \mathrm{~g}^{-1}\right)$ & 134,97 & 135,21 & 135,28 & 135,30 \\
\hline Índice de saponificação $\left(\mathrm{mg} \mathrm{KOHg}^{-1}\right)$ & 193,26 & 193,04 & 192,97 & 192,90 \\
\hline
\end{tabular}

Valores são médias (desvio padrão) $(n=3)$.

${ }^{a}$ Médias na mesma linha com o mesmo sobrescrito não diferem entre si $(\mathrm{P}>0,05)$ pelo teste de Tukey.

${ }^{1}$ Expresso como ácido oleico

ND: não detectado.

RDC 270 (ANVISA, 2005) para óleos extraídos por prensagem, que é de $2 \%$ de acidez e $15 \mathrm{meqkg}^{-1}$ de peróxidos. A umidade do óleo obtida no tratamento de $1,2 \mathrm{kgh}^{-1}(0,26 \%)$ foi significativamente maior $(\mathrm{P}<0,05)$ em relação aos outros tratamentos. Isto pode ser explicado pela maior condensação e arraste de água pelo óleo em função do maior espaço livre no interior da prensa. No Codex Alimentarius (FAO/ WHO, 2001), a umidade máxima para os óleos deve ser menor que $0,2 \%$.

Não houve diferença significativa $(\mathrm{P}>0,05)$ na composição em ácidos graxos entre os tratamentos realizados (Tabela 3). Os teores de ácido linoleico
(C18:2) variaram de 69,23 a $69,42 \%$ enquanto os de ácido oleico (C18:1) variaram de 15,88 a 15,93\% entre os tratamentos. Estes dados estão em linha com os resultados relatados na literatura por outros autores (FERRARI et al., 2004; LOPES et al., 2010; REGIS, 2010) para óleo de semente de maracujá Passiflora edulis. Em relação a outros óleos obtidos de sementes oleaginosas, os teores de ácido linoleico (C18:2) e oleico (C18:1) do óleo da semente de maracujá são semelhantes aos teores encontrados no óleo de girassol de alto linoleico, enquanto os teores dos ácidos palmítico (C16:0) e esteárico (C18:0) são semelhantes aos obtidos no óleo de soja (FAO/

Tabela 3 - Perfil de ácidos graxos de óleo de semente de maracujá ( $\left.\mathrm{g} 100 \mathrm{~g}^{-1}\right)$ extraído por prensagem sob diferentes taxas de alimentação.

\begin{tabular}{|c|c|c|c|c|}
\hline \multirow{2}{*}{ Ácido graxo } & \multicolumn{4}{|c|}{ de anment } \\
\hline & $1,2 \mathrm{kgh}^{-1}$ & $1,8 \mathrm{kgh}^{-1}$ & $2,4 \mathrm{kgh}^{-1}$ & $3,0 \mathrm{kgh}^{-1}$ \\
\hline C16:0 & $10,59(0,01)^{\mathrm{a}}$ & $10,57(0,02)^{\mathrm{a}}$ & $10,62(0,01)^{\mathrm{a}}$ & $10,61(0,01)^{\mathrm{a}}$ \\
\hline C16:1 & $0,19(0,00)^{\mathrm{a}}$ & $0,19(0,00)^{\mathrm{a}}$ & $0,19(0,00)^{\mathrm{a}}$ & $0,19(0,00)^{\mathrm{a}}$ \\
\hline C18:0 & $3,07(0,01)^{\mathrm{a}}$ & $3,06(0,01)^{\mathrm{a}}$ & $3,06(0,01)^{\mathrm{a}}$ & $3,05(0,01)^{\mathrm{a}}$ \\
\hline C18:1 & $15,93(0,02)^{\mathrm{a}}$ & $15,92(0,03)^{a}$ & $15,88(0,02)^{\mathrm{a}}$ & $15,88(0,01)^{\mathrm{a}}$ \\
\hline C18:2 & $69,23(0,12)^{\mathrm{a}}$ & $69,36(0,07)^{\mathrm{a}}$ & $69,42(0,02)^{\mathrm{a}}$ & $69,41(0,05)^{\mathrm{a}}$ \\
\hline $\mathrm{C} 20: 0$ & $0,17(0,00)^{\mathrm{a}}$ & $0,17(0,00)^{\mathrm{a}}$ & $0,17(0,00)^{\mathrm{a}}$ & $0,17(0,00)^{\mathrm{a}}$ \\
\hline $\mathrm{C} 18: 3$ & $0,43(0,01)^{\mathrm{a}}$ & $0,43(0,01)^{\mathrm{a}}$ & $0,43(0,01)^{\mathrm{a}}$ & $0,42(0,00)^{\mathrm{a}}$ \\
\hline $\mathrm{C} 20: 1$ & $0,11(0,01)^{\mathrm{a}}$ & $0,11(0,00)^{\mathrm{a}}$ & $0,11(0,00)^{\mathrm{a}}$ & $0,10(0,01)^{\mathrm{a}}$ \\
\hline Sinsat ${ }^{1}$ & 85,89 & 86,01 & 86,03 & 86,02 \\
\hline$\Sigma \mathrm{sat}^{2}$ & 13,82 & 13,81 & 13,85 & 13,84 \\
\hline
\end{tabular}

Valores são médias (desvio-padrão) $(\mathrm{n}=3)$.

${ }^{a}$ Médias na mesma linha com o mesmo sobrescrito não diferem entre si $(\mathrm{P}>0,05)$ pelo teste de Tukey.

${ }^{1}$ Insat = soma de ácidos graxos insaturados.

${ }^{2}$ Sat $=$ soma de ácidos graxos saturados. 
WHO, 2001). O teor de ácido linolênico (C18:3) é baixo, o que representa um fator favorável do ponto de vista da estabilidade oxidativa. Os ácidos graxos linoleico e linolênico são ácidos graxos essenciais e o óleo de semente de maracujá é abundante em relação ao primeiro e deficiente em relação ao segundo. Atualmente este óleo tem sido avaliado quanto ao seu uso em aplicações terapêuticas sem resultados publicados até o momento. No entanto, a maior demanda ainda é das indústrias de perfumaria e toalete e, quando atende a determinadas características de qualidade e estabilidade, este óleo pode ser comercializado por valores que chegam a US $\$ 13,00$ por quilograma (REIS, 2013 - Informe verbal).

\section{CONCLUSÃO}

Houve diferença na qualidade e na temperatura de saída do óleo no processo de prensagem em função da taxa de alimentação, fator este que deve ser avaliado em equipamentos em maior escala. A qualidade do óleo depende de condições adequadas de extração, visto que a estabilidade oxidativa do óleo não é elevada e a acidez deve ser controlada. Além disso, deve ser dispensado um tratamento adequado para as sementes, já que, após o despolpamento, em geral, são descartadas pelas fábricas produtoras de suco.

\section{INFORME VERBAL} Itabapoana, RJ. Brasil.

REIS, S.L.R. Extrair - Óleos Naturais. Bom Jesus do

\section{REFERÊNCIAS}

AMERICAN OIL CHEMIST'S SOCIETY - AOCS. Official methods and recommended practices of the American Oil Chemists' Society. Champaign, 2009, 1200p.

ANTONIASSI, R. Prensagem em pequena escala. Árvore do conhecimento, Tecnologia de alimentos. Agência Embrapa de Informação Tecnológica. Acesso em: 16 jul. 2013. Online. Disponível em: <http://www.agencia.cnptia.embrapa.br/gestor/ tecnologia_de_alimentos/Abertura.html\#>.

ANVISA. Resolução RDC ANVISA/MS n.270, de 22 de setembro de 2005. Aprova o Regulamento técnico para óleos vegetais, gorduras vegetais e creme vegetal. Diário Oficial da União, s.1, 2005. Disponível em: <http://www.anvisa.gov.br/e-legis $>$. Acesso em: 22 jul. 2013.

DGF. Deutsche einheitsmethoden zur untersuchung von fetten, fettprodukten und verwandten stiffen. Stuttgart: Münster, Wissenchaftliche Verlagsgesellschaft mbH, 1984, 360p.

DHAWAN, K. et al. Passiflora: a review update. Journal of Ethnopharmacology, v.94, p.1-23, 2004. Disponível em: <http:// dx.doi.org/10.1016/j.jep.2004.02.023>. Acesso em: 22 jul. 2013.
FAO/WHO. Codex Alimentarius: fats, oils and related products. 2 ed. Rome, 2001. V.8. 80p.

FERRARI, R.A. et al. Caracterização de subprodutos da industrialização do maracujá - aproveitamento das sementes. Revista Brasileira de Fruticultura, v.26, n.1, p.101-102, 2004. Disponível em: <http://dx.doi.org/10.1590/S0100-29452004000100027>. Acesso em: 16 jul. 2013.

GALANAKIS, C.M. Recovery of high added-value components from food wastes: Conventional, emerging technologies and commercialized application. Trends in Food Science \& Technology, v.26, p.68-87, 2012. Disponível em: <http://dx.doi. org/10.1016/j.tifs.2012.03.003>. Acesso em: 22 jul. 2013.

HARTMAN, L.; LAGO, R.C.A. A rapid preparation of fatty acid methyl esters from lipids. Laboratory Practice, v.22, n.8, p.475476, 1973.

INSTITUTO BRASILEIRO DE GEOGRÁFIA E ESTATÍSTICA (IBGE). Produção Agrícola Municipal - Culturas Temporárias e permanentes. Acesso em: 28 maio 2013. Online. Disponível em: $<$ http://www.ibge.gov.br/home/estatistica/economia/pam/2011/ default.shtm>.

KARAJ, S.; MULLER, J. Optimizing mechanical oil extraction of Jatropha curcas L. seeds with respect to press capacity, oil recovery and energy efficiency. Industrial Crops and Products, v.34, p.1010-1016, 2011. Disponível em: <http://dx.doi.org/10.1016/j. indcrop.2011.03.009>. Acesso em: 22 jul. 2013.

LOPES, R.M. et al. Estudo comparativo do perfil de ácidos graxos em semente de passifloras nativas do cerrado brasileiro. Revista Brasileira de Fruticultura, v.32, n.2, p.498-506, 2010. Disponível em: <http://dx.doi.org/10.1590/S0100-29452010005000065>. Acesso em: 22 jul. 2013.

LÓPEZ-VARGAS, J.H. et al. Chemical, physico-chemical, technological, antibacterial and antioxidant properties of dietary fiber powder obtained from yellow passion fruit (Passiflora edulis var. flavicarpa) co-products. Food Research International, v.51, p.756-763, 2013. Disponível em: <http://dx.doi.org/10.1016/j. foodres.2013.01.055>. Acesso em: 16 jul. 2013.

MALACRIDA, C.R.; JORGE, N. Yellow passion fruit seed oil (Passiflora edulis f. flavicarpa): physical and chemical characteristics. Brazilian Archives of Biology and Technology, v.55, n.1, p.127134, 2012. Disponível em: <http://dx.doi.org/10.1590/S151689132012000100016>. Acesso em: 10 jan. 2013.

OLIVEIRA, E.M.S. et al. Caracterização dos resíduos da polpa do maracujá-amarelo. Ciência Rural, v.41, n.4, p.725730, 2011. Disponível em: <http://dx.doi.org/10.1590/S010384782011005000031>. Acesso em: 16 jul. 2013.

OLIVEIRA, L.C. et al. Caracterização e extração de compostos voláteis de resíduos do processamento de maracujá (Passiflora edulis Sims f. flavicarpa Degener). Ciência Rural, v.42 n.12, p.2280-2287, 2012. Disponível em: <http:// dx.doi.org/10.1590/S0103-84782012005000103>. Acesso em: 22 jul. 2013.

PIGHINELLI, A.L.M.T. et al. Otimização da prensagem a frio de grãos de amendoim em prensa contínua tipo expeller. Ciência e 
Tecnologia de Alimentos, v.28, p.66-71, 2008. Disponível em: $<\mathrm{http}$ :/dx.doi.org/10.1590/S0101-20612008000500011>. Acesso em: 22 jul. 2013

REGIS, S.A. Rendimento e qualidade do óleo das sementes em função dos estádios de maturação dos frutos e do processo de purificação do resíduo de maracujá. 2010. 59f. Dissertação
(Mestrado em Produção Vegetal) - Universidade Estadual do Norte Fluminense Darcy Ribeiro, RJ.

WHITE, P. J. Conjugated diene, anisidine value, and carbonyl value analyses. In: WARNER, K.W.; ESKIN, N.A.M. Methods to assess quality and stability of oils and fat-containing foods. Champaign : American Oil Chemists' Society, 1995. p.159-178. 